\title{
Laparoscopic Anatrophic Nephrolithotomy a Feasible Option in Staghorn Calculi
}

\author{
Gómez RF ${ }^{1}$, Manzo PB ${ }^{2}$, Jaime BC ${ }^{3}$, Mario $\mathrm{SO}^{3}$, Leopoldo $\mathrm{LB}^{1}$, Salvador $\mathrm{NNA}^{1}$ and Almanzor GO ${ }^{3 *}$ \\ 1Urology Resident in hospital civil de Guadalajara, Fray Antonio Alcalde, USA \\ 2Endourology Service, Hospital Regional de Alta Especialidad del Bajío, USA \\ 3Urology Service, Hospital civil de Guadalajara, Fray Antonio Alcalde, USA
}

Submission: September 19, 2017; Published: November 10, 2017

*Corresponding author: Almanzor GO, Urology Service, Hospital Civil de Guadalajara, Fray Antonio Alcalde, USA,

Email: octavioalmanzor@gmail.com

\begin{abstract}
Introduction: Management of stag horn calculi still being real challenge for urologists dedicated to stone management. Nowadays it is difficult to obtain a free stone rate with a single procedure in these complex cases even with the recent advances in endourology. The aim of this study is to present our results and review of published case series in PubMed.

Patients and method: We reported our experience in laparoscopic anatrophic nephrolithotomy in 8 patients with stag horn calculi diagnosis between 2014-2015. We evaluated patient variables like age, stone size, surgical time, blood loss, transfusion, complications, hospitalization days and free stone rate. And we performed a comparison with previous case series published. It is worth highlighting that the same surgeon performed all surgeries.
\end{abstract}

Results: A total of 8 patients undergo to laparoscopic anatrophic nephrolithotomy, patients mean age was 42.1 years, stone size $52.63 \mathrm{~mm}$, surgical time $127.5 \mathrm{~min}$, warm ischemia 29.5 minutes, blood loss $218.7 \mathrm{ml}$, transfusion rates $0 \%$, complications $25 \%$, hospitalization days 3.5 days and stone free rate was $75 \%$.

Conclusion: Laparoscopic anatrophic nephrolithotomy could be a feasible option in high volume centers to patients with complex renal stones that will require multiple percutaneous and endourologic procedures, or those who are no candidates to percutaneous nephrolithotomy. Achieving laparoscopic anamorphic nephrolithotomy a reasonably stone free rate with one procedure.

Abbrevations: PCNL: Percutaneous Nephrolithotomy; SWL: Shock Wave Lithotripsy; LAN Laparoscopic Anatrophic Nephrolithotomy ; OAN: Open Anatrophic Nephrolithotomy

\section{Introduction}

Management of stag horn calculi is still a big challenge for urologist dedicated to stone treatment, even with the recent advances in endourology it is difficult to obtain a stone free rate of $100 \%$ with a single procedure. Endourological techniques have revolutionized the treatment of urinary stones to the point that open surgery has become anachronistic [1]. Laparoscopic surgery could be considered in selected patients like those who has a big stone burden, associated renal malformations, or in those who endourological techniques has previously failed or will require multiple endourology procedures [2-4]. Stag horn calculi are defined as those stones that fill up the majority of renal collecting system, occupying renal pelvis and branching out into most calyces [3]. In the present study we describe our results, surgical technique and we made a literature research and review, with the purpose to compare ours results to previous case series already published in PubMed.

\section{Patients and Methods}

We included all patients with a stag horn calculi diagnosis and undergo laparoscopic anatrophic nephrolithotomy (LAN) between January 2014 to January 2015 at Hospital Civil Fray Antonio Alcalde. In this study we reported our initial experience with this procedure, patient characteristics that were evaluated include demographic data (age) stone features (size, volume, density, laterality), intra operative variables (surgical time, blood loss, transfusion rate, complications), post operative variables (hospitalization days, complications, transfusion and stone free rate). It is worth highlighting that all procedures were done by the same surgeon and all patients signed informed consent 
before surgery, were undergone to preoperative anesthesia evaluation and to a CT scan with non-contrast with the purpose to evaluate stone size and anatomical features.

All patients were admitted on the day before surgery and every one received prophylaxis with intravenous antibiotics [1] hour before surgery. In the postoperative period patients were subjected to a non-contrast low dose CT scan to confirm stone free rate (defined as no fragments of $>4 \mathrm{~mm}$ ) [5]. In all patients Foley catheter was removed before the discharge, Jackson-Pratt type drainage was removed when the 24 hour output was less than $50 \mathrm{ml}$ and the double $\mathrm{J}$ catheter was removed two weeks after procedure with local anesthesia if the patients was 100\% Stone free rate. We performed a research for the serial cases publish in the data base PubMed texting the words "Laparoscopic" AND "Anatrophic AND "Nephrolithotomy" with the filter in article type selecting Journal Article, we excluded those articles with only one patient (case reports) and the surgeries performed with the robot.

\section{Laparoscopic technique}

All procedures were performed under general anesthesia and a double J catheter was placed in all cases at the beginning of surgery, thereafter every patient was placed in lateral decubitus position. For left side we used 4 trocars, but if the procedure is on the right side we added a $5 \mathrm{~mm}$ trocar with the purpose of liver retraction. The first trocar placed is a $10 \mathrm{~mm}$ trocar, that is used for the 30 degrees lens, and anatomically it is placed in the pararectal line $3-4 \mathrm{~cm}$ above the navel, the second trocar is a $10 \mathrm{~mm}$ diameter and it is inserted $8-9 \mathrm{~cm}$ to the right of the first trocar, the third trocar is of $5 \mathrm{~mm}$ and placed to the left of the first trocar about $8-9 \mathrm{~cm}$ so these three trocars form an imaginary triangle. The fourth trocar, occasionally, is placed on the axillary posterior line as a support, for renal retraction and if the procedure is on the right side, an additional $5 \mathrm{~mm}$ trocar is placed to retract the liver.

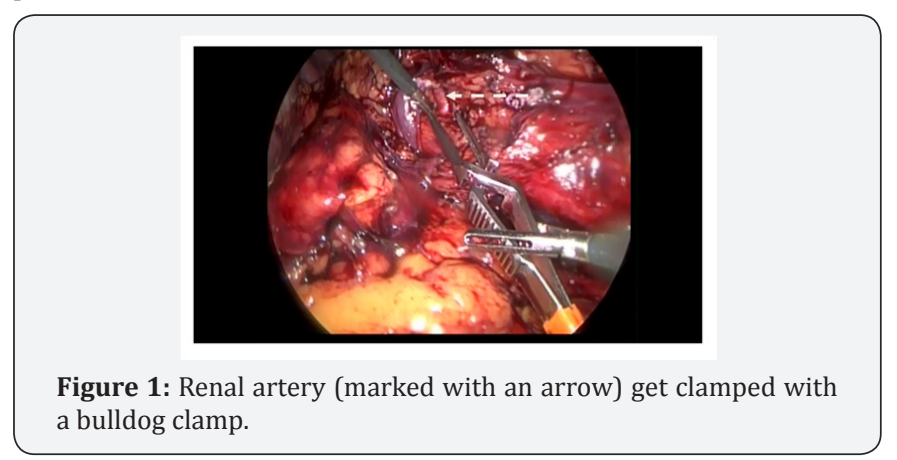

A transperitoneal approach was performed in all patients and the first step once trocars are placed is to fall out told's fascia, with mobilization of colon and other structures such as duodenum and liver if we are on the right side. Dissection was continued until the renal hilum was exposed so can be adequately prepared to be clamped. Thereafter the dissection of the perirenal fat of the anterior and posterior segment was done with the purpose of discover the renal capsule and could have an adequate exposure of both sides of the kidney and renal hilum. The next step was to clamp the renal artery (only) with a bulldog clamp Figure 1 and to increase the pneumoperitoneum to $20 \mathrm{mmHg}$, to reduce the bleeding with by an increase peritoneal pressure (the rest of the surgery worked with $14 \mathrm{mmHg}$ ).

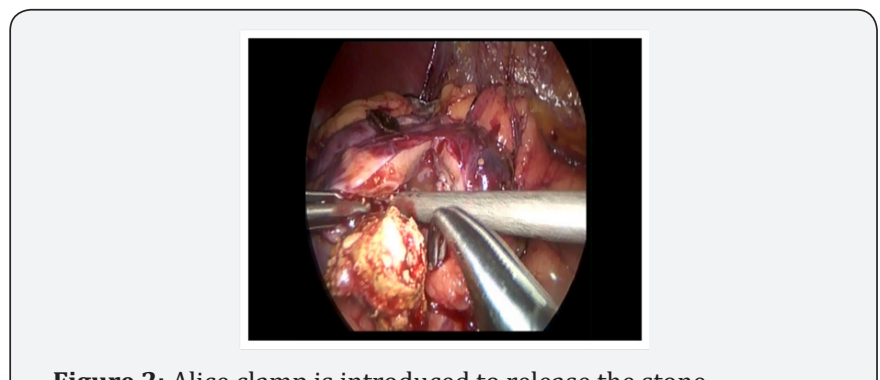

Figure 2: Alice clamp is introduced to release the stone.
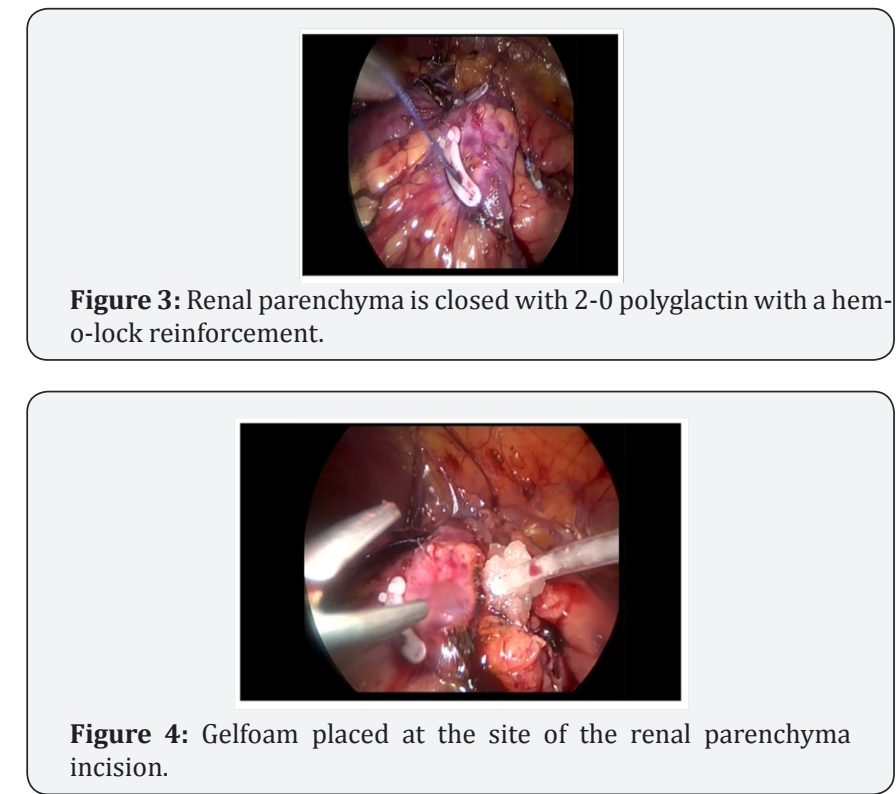

Once intra abdominal pressure increase to $20 \mathrm{mmHg}$ a laparoscopic scalpel (blade number 11) was prepared to perform the incision in the renal parenchyma and a $3-4 \mathrm{~cm}$ renal incision was performed trying to identify the avascular line of Brodel, which is difficult to identify because of its irregularities in its path [6]. Once the collector system is opened and the stone is exposed, an Alice clamp is introduced to release the stone, taking care of remove the stone in one piece (Figure 2). Thereafter collector system is then explored with a 30-degree lens for residual stone. As a final step prior to removal of the bulldog clamp, renal parenchyma is sutured with a 2-0 polyglactin reinforced with a hem-o-lock (Figure 3), after completing the suture, the bulldog clamp was removed with the purpose of evaluate presence of bleeding, there was some bleeding detected, additional " $X$ " suture points and Gelfoam were placed at the site of renal parenchyma incision (Figure 4). It is very important to consider that warm ischemia should be less than 30 minutes because previous reports, have postulated that a prolonged 
ischemia causes greater renal damage [6]. Finally Jackson-Pratt type drainage was left in place.

\section{Results}

A total of eight patients were undergo to laparoscopic anatrophic nephrolithotomy, mean patients age were 42.1 years, stone diameter was $52.6 \mathrm{~mm}, 5$ stones $(62.5 \%)$ were found in left topography and 3 stones (37.5\%) were in the right topography, mean surgical time 127.5 minutes [7,8], warm ischemia time 29.5 minutes, blood loss average $218.7 \mathrm{ml}$, transfusion rate $0 \%$,

Table 1: Patient characteristics.
2 complications (25\%), we decided to perform a nephrectomy in a patient due to prolonged ischemia and one patient was discharge with no complications but he returns to the emergency room with gross hematuria [9] days postoperatively, which did not yield to medical treatment also the non-availability to performed an angiography + embolization (high suspicion of pseudoaneurisma). Stone free rate was $75 \%$, length in hospital were 3.5 days. The same surgeon performed all the surgeries (Table 1).

\begin{tabular}{|c|c|c|c|c|c|c|c|c|c|}
\hline \#Patient & $\mathbf{1}$ & $\mathbf{2}$ & $\mathbf{3}$ & $\mathbf{4}$ & $\mathbf{5}$ & $\mathbf{6}$ & $\mathbf{7}$ & $\mathbf{8}$ & Mean \\
\hline Age & 33 & 31 & 40 & 47 & 38 & 46 & 44 & 58 & 42.13 \\
\hline $\begin{array}{c}\text { Stone } \\
\text { Diameter(mm) }\end{array}$ & 42 & 50 & 65 & 46 & 45 & 48 & 60 & 65 & 52.63 \\
\hline Side & L & L & R & L & R & L & L & R & NV \\
\hline Operative Time & 110 & 110 & 150 & 90 & 110 & 110 & 110 & 230 & 127.5 \\
\hline WIT & 25 & 14 & 32 & 30 & 25 & 30 & 35 & 45 & 29.5 \\
\hline Blood Loss & 150 & 100 & 550 & 200 & 150 & 300 & 150 & 150 & 218.75 \\
\hline Transfusion & No & No & No & No & No & No & No & Yes & $0 \%$ \\
\hline SWT & 4 & 4 & 6 & 6 & 6 & 12 & 12 & 4 & 6.75 \\
\hline Complications & No & No & No & No & Yes* & No & No & Yes** & $75 \%$ \\
\hline Stone Free Rate & SI & SI & SI & SI & SI & No & SI & No & $75 \%$ \\
\hline HSD & 4 & 3 & 3 & 3 & 4 & 4 & 4 & 3 & 3.5 \\
\hline
\end{tabular}

In our research in PubMed we obtain 14 results of those we only found 4 serial cases that performed LAN: Simforoosh [5,6] number of patients 24, mean surgical time 202 minutes, ischemia 30 minutes, stone burden $61 \mathrm{~mm}$, stone free rate $88 \%$, no complications; Zhou [8] number of patients 11 , mean surgical time 139, ischemia 31 minutes; stone burden 52 $\mathrm{mm}$, stone free rate $90.9 \%$, complications 3 urinary leakage.

Table 2: Serial cases characteristics.

\begin{tabular}{|c|c|c|c|c|c|c|}
\hline Author & $\begin{array}{c}\text { Number of } \\
\text { Patients }\end{array}$ & MST & $\begin{array}{l}\text { Ischemia } \\
\text { Time }\end{array}$ & SB & FSR & Complications \\
\hline Zhou (2011) & 11 & 139 & 31 & 52 & 90.9 & Urinary Leakage(3) \\
\hline Gield Man(2012) & 8 & 142.5 & 20.8 & 53 & $62.50 \%$ & Vascular Fistual (1) \\
\hline Simforoosh(2013) & 24 & 202 & 30 & 61 & $88 \%$ & $\mathrm{~Np}(1)$ \\
\hline Aminsharifi(2013) & 10 & 192 & 32.8 & 67.3 & $86 \%$ & Spleen Injury \\
\hline Our Syudy & 8 & 127.5 & 29.5 & 52.6 & $75.00 \%$ & $\mathrm{~Np}(2)$ \\
\hline
\end{tabular}

\section{Discussion}

We know that stag horn calculi is a real challenge for all urologists that are dedicated to renal stone management, the main purpose treatment is to obtain a complete clearance (stone free rate of $100 \%$ ), because they are related to infection an incomplete removal will produce recurrence $[10,11]$, staghorn renal calculi can destroy not only renal function, but also general health. American Urological Association guidelines 2016 state that the first line treatment for stag horn calculi is percutaneous nephrolithotomy [12] (PCNL) because in respect
Gieldman [9] number of patients 8, mean surgical time 142.5 minutes, ischemia 20.8 minutes, stone burden $53 \mathrm{~mm}$, stone free rate $62.5 \%$, complications one vascular fistula; Aminsharifi [10] number of patients 10 , mean surgical time 127.5 minutes, ischemia 32.8 minutes, stone burden $52.6 \mathrm{~mm}$, stone free rate $85.7 \%$, complications spleen injury (Table 2). to open surgery, PCNL has demonstrated comparable stone-free rates but it offers lower morbidity evidenced by decreased intra operative and postoperative complications, decreased length of hospital stay, earlier return to work, and much smaller surgical incision [13-15].

Multiple treatments have been proposed for stag horn calculi in an older trail comparing PNCL in combination with shock wave lithotripsy (SWL) and SWL as monotherapy, Meretyk et al. [16] found a better free stone rates with combination therapy, and the rate of sepsis was higher in monotheraphy. In our study 
we found that in the index data they are only 5 studies (including ours) with a total of 61 patients undergo LAN, in this data the who has more experience is Simforoosh et al. [5] with 24 patients; the mean surgical time in our study was 127.5 minutes, compared with the mean time in the other studies 168 minutes (range 139-202 minutes). The highest Stone rate was achieved by Zhou et al. [8] with a $90.9 \%$, where in a low range with $75 \%$ this may be due some studies use alternatives options and do not performed CT scan for Stone free rate evaluation.

There's big laparoscopic series like Qin who performed 75 cases, in patients with a large stone but the surgery they apply was pyelolithotomy with a $92 \%$ stone free rate, but with a high rate of complications [13]. It's no easy to get a high free stone rate King et al. [17] performed seven robot-assisted anatrophic nephrolithotomy achieve only $27 \%$. Making a comparison between LAN and open anatrophic nephrolithotomy (OAN) in stone free rate OAN reported $71 \%$ [16], the rate obtained with LAN is $80.4 \%$ (average of 5 studies). Similar results in stone free rate but as we can see in this study decreased length of hospital stay (3.5 days), less pain, less transfusion rate, make LAN a feasible option to treat stag horn calculi in experimented laparoscopic centers. The laparoscopic approach is a minimally invasive alternative to endourologic treatment in some special conditions for example: Stag horn calculi + retrocaval ureter, stones surgery that need an extra ablative and reconstructive therapy (like pyeloplasty $[15,18]$, patient do not accept multiple procedures with PCNL or if the kidney had unusually complex anatomy [19], multiple failed endourological procedures, etc. Many treatments have been proposed to treat stag horn calculi, but there no one that achieve a $100 \%$ stone free rate, all procedures have complications, so patient and doctor will have to discuss all available options and choose the best option for each case [20-22].

\section{Conclusion}

LAN could be feasible option, in those patients who are no candidates to PCNL or other endourologic procedures, achieving a reasonable stone free rate with a single procedure [23]. It should be noted that LAN is an advanced laparoscopic procedure and should be performed by expert laparoscopists. Furthermore it is necessary a randomize controlled trial comparing percutaneous nephrolithotomy and laparoscopic anatrophic nephrolithotomy to evaluate real advantages and disadvantages.

\section{References}

1. Andrei N, Oscar S, Roy M, Ramon J, Winkler H (2009) Laparoscopic Surgery for Renal Stones: Is it Indicated in the Modern Endourology Era? Int Braz J Urol 35(1): 9-17.

2. Alivizatos G, Skolarikos A (2006) Is there still a role for open surgery in the management of renal stones? Curr Opin Urol 16(2): 106-111.

3. Melissougos N, Davilas E, Fragoulis A (2016) Complete staghorn calculus disease- Does it still have a place? Scan J Urol Nephrol 36(6): 426-430.
4. Jeon SH, Kwon TG, Rha KH, Sung GT, Lee W, et al. (2011) Comparision of laparoscopic versus open radical nephrectomy for large renal tumor: A retrospective analysis of multi-center results. BJU Int 107(5): 817-821.

5. Simforoosh N, Aminsharifi A, Tabibi A, Akbar NA, Saeed Z, et al. (2008) Laparoscopic anatrophic nephrolithotomy for managing large staghorn calculi. BJU Int 101(10): 1293-1296.

6. Simforoosh N, Radfar M, Nouralizadeh A, Tabibi A, Basiri A, et al. (2013) Laparoscopic Anatrophic Nephrolithotomy for Management of Staghorn Renal Calculi. J Laparoendosc Adv Surg Tech 23(4): 306-310.

7. Hemal AK (2011) Laparoscopic retroperitoneal extirpative and reconstructive renal surgery. J Endourol 25(2): 209-216.

8. Zhou L, Xuan Q, Wu B, Xiao J, Dong X, et al. (2011) Retroperitoneal laparoscopic anatrophic nephrolithotomy for large staghorn calculi. Int J Urol 18(2): 126-129.

9. Giedelman C, Arriaga J, Carmona, de Andrade R, Banda E, et al. (2012) Laparoscopic Anatrophic Nephrolithotomy: Developments of the Technique in the era of minimally invasive surgery. J Endourol 26(5): 444-450.

10. Aminsharifi A, Hadian P, Boveiri K (2013) Laparoscopic Anatrophic Nephrolithotomy for Management of Complete Stagorn Renal Stone: clinical efficacy and intermediate-term functional outcome. J Endourol 27(5): 573-578.

11. Matlaga BR, Lingeman JE (2011) Surgical management of upper urinary tract calculi. In: Wein AJ, Kavoussi LR, Novick AC, Partin AW, Peters CA (Eds.), Campbell-Walsh Urology. $\left(10^{\text {th }}\right.$ edn.) Philadelphia: Saunders Elsevier, pp. 1357-1410.

12. Assimos D, Krambeck A, Miller N, Monga M, Murad MH, et al. (2016) Surgical management of stones: american urological association/ endourological society guideline. J Urol 196(4):1153-1160.

13. Preminger GM, Assimos DG, Lingeman JE, Nakada SY, Pearle M, et al (2005) Chapter 1: AUA guideline on management of staghorn calculi: diagnosis and treatment recommendations. J Urol 173(6): 1991-2000.

14. Al-Kohany KM, Shokeir AA, Mosbah A, Mohsen T, Shoma AM, et al. (2005) Treatment of complete staghorn stones: a prospective randomized comparison of open surgery versus percutaneous nephrolithotomy. J Urol 173(2): 469-473.

15. Qin C, Wang S, Li P, Cao Q, Shao P, et al. (2014) Retroperitoneal laparoscopic technique in treatment of complex renal stones: 75 cases. BMC Urol 14: 16.

16. Meretyk S, Gofrit ON, Gafni O, Pode D, Shapiro A, et al. (1997) Complete staghorn calculi: random prospective comparison between extracorporeal shock wave lithotripsy monotherapy and combined with percutaneous nephrostolithotomy. J Urol 157(3): 780-786.

17. King S, Klaassen Z, Madi R (2014) Robot-assisted anatrophic nephrolithotomy: Description of technique and early results. J Endourol 28(3): 325-329.

18. Hemal AK, Nayyar R, Gupta NP, Dorairajan LN (2010) Experience with robotic assisted laparoscopic surgery in upper tract urolithiasis. Can J Urol 17(4): 5299-5305.

19. Preminger GM, Assimos DG, Lingerman Je (2005) Report on the Management of Staghorn Calculi. AUA Guidelines.

20. Desai M, De Lisa A, Turna B, Rioja J, Walfridsson H, et al. (2011) The clinical research office of the endourological society percutaneous nephrolithotomy global study: Staghorn versus nonstaghorn stones. J Endourol 25: 1263-1268.

21. Armitage JN, Irving SO, Burgess NA (2012) Percutaneous nephrolithotomy in the United Kingdom: Results of a pro- spective data registry. Eur Urol 61(6): 1188-1193. 
22. Segura JW, Preminger GM, Assimos DG, Dretler SP, Kahn RI, et al. (1994) Nephrolithiasis Clinical Guidelines Panel summary report on the management of staghorn calculi. J Urol 151(6): 1648-1651.

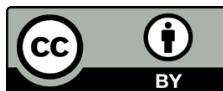

This work is licensed under Creative Commons Attribution 4.0 License Commons Attribution 4.0 License
DOI: $10.19080 /$ JOJUN.2017.04.555634
23. Bhupendra P and Urmila DR (2013) Laparoscopic Anatrophic Nephrolithotomy: Developments of the Technique in the Era of Minimally Invasive Surgery. Journal of Endourology and Videourology 27(1): 108- 108.

\section{Your next submission with Juniper Publishers} will reach you the below assets

- Quality Editorial service

- Swift Peer Review

- Reprints availability

- E-prints Service

- Manuscript Podcast for convenient understanding

- Global attainment for your research

- Manuscript accessibility in different formats

( Pdf, E-pub, Full Text, Audio)

- Unceasing customer service

Track the below URL for one-step submission https://juniperpublishers.com/online-submission.php 